\title{
Radio language teaching in Kenyan schools
}

\section{Maurice Imhoof}

\begin{abstract}
The Radio Language Arts Project in Kenya is currently testing the feasibility of using radio intensively to serve as the major medium of English instruction in the formal classroom setting. The project, now in its third and final year of lesson development and experimentation, is evaluating the effectiveness of radio in teaching English to children in the first three primary grades. The thirty-minute, daily broacasts are part of the normal school curriculum. Preliminary results show substantial achievement gains by the radio students and strong support from school personnel. The project demonstrates that carefully designed, written, and produced radio lessons, aided by human interaction fostered by a teacher or other guide, can be an effective alternative to more complex and more costly techniques.
\end{abstract}

In Kenia word die uitvoerbaarheid daarvan om die radio intensief te gebruik as die belangrikste medium by die onderrig van Engels in die formele klassituasie, getoets deur projek "Radio Language Arts". Die projek, wat tans in sy derde en finale jaar van lesontwikkeling en eksperimentasie verkeer, evalueer die doeltreffendheid van die radio in Engels-onderrig aan kinders in die eerste drie jaar van die primêre skool. Die halfuur lange, daaglikse uitsendings vorm deel van die normale kurrikulum. Voorlopige resultate vertoon aansienlike winste in die prestasies van radio-leerlinge en 'n sterk aanhang deur personeel. Die projek demonstreer dat noukeurig ontwerpte, geskrewe en uitgevoerde radio-lesse, ondersteun deur menslike interaksie in die vorm van 'n onderwyser of gids, 'n doeltreffende alternatief kan wees vir meer ingewikkelde en duur metodes.

\section{Overview}

The Radio Language Arts Project (RLAP) is a research and development project designed to test the feasibility of using radio as the major medium of instruction in teaching English in the first three primary grades. (The project is a joint venture between Kenya and the United States. The Kenyan executing agency is the Kenya Institute of Education, as authorised by the Ministry of Education, Science and Technology. The American executing agency is the Academy for Educational Development, under contract to the United States Agency for International Development. Major funding comes from USAID.) The primary significance of the RLAP for the study of media and language teaching is its emphasis on the intensive use of radio to serve as the major medium of instruction in the formal classroom setting. The project, now in its third and final year of lesson development, is systematically evaluating the effectiveness of formal, intensive radio programmes in teaching English as a foreign language to young children. The techniques used to achieve these results are being carefully documented, since there is little hard evidence or detailed methodological description of successful radio language teaching available in the literature at present.

Language programmes are broadcast as part of the normal school curriculum during school hours. The daily thirty-minute lessons fit into the regular English period in the school time-table. Although radio is the major medium of instruc- 
tion, teachers play an important role during the broadcasts, and in pre- and post-broadcast activities. The radio lessons are designed to assist teachers in the classroom, enhancing their effectiveness in teaching a difficult and important skill.

The project design draws on the results of several relevant projects in other countries, most particularly a radio-based primary-school mathematics project conducted between 1973 and 1978 in Nicaragua, Central America (Friend, Searle \& Suppes 1980). It also builds on Kenya's extensive experience with educational broadcasts to schools which use radio in a supplementary rather than intensive role.

\section{Research design}

The RLAP research design uses a sample of thirty-one schools drawn from seven linguistic districts. Given the supposed importance of mother tongue as a variable in learning English, the districts chosen represent the major language groups and approximately seventy percent of the Kenya population. Schools were chosen by means of a stratified random sample on the basis of performance on the standardised primary school leaving examination, with equal representation from high, medium and low scoring schools.

The thirty-one project schools are divided into two groups. Ten schools are designated as observation schools in which radio lessons are observed to identify instructional problems with the radio lessons. The other twenty-one schools--three from each district-are used to test the effectiveness of the lessons in improving pupil performance.

\subsection{Formative evaluation}

Formative evaluation is an integral part of the instructional development process. It applies a technique developed by the Radio Mathematics Project based on the feedback system used in industry to control continuous processes (Friend 1980). As applied in the RLAP, this model is labelled the feedforward revision system to underscore its emphasis on improving instruction through changes to future lessons. A team of two observers (professionals from the field working with the project on a part-time basis) is assigned to each of the ten observation schools. They observe three lessons each week, completing an observation form developed by the project staff which focuses attention on the instructional methodology (teacher performance, pupil participation, common mistakes, and so on). They also talk to teachers and headmasters. The RLAP staff, which writes and produces the radio lessons, also observes once a week. Every Friday, the observers administer an achievement test which focuses on objectives that have been introduced or maintained during the week.

Formative evaluation data are compiled, analysed, and summarised by the RLAP research specialist, who then presents the results to his colleagues. Problems are discussed and decisions are made about correction. In some cases, a specific problem will be solved by writing a limited number of segments to correct it. In other cases, a general concern will be raised, which may result in a new instructional design principle to be applied throughout future lessons.

When serious problems arise, of course, decisions are made to change lessons that have already been recorded. A segment which is observed to fail completely, leaving pupils confused and not participating, would evoke such a decision. But the emphasis of the feedforward formative evaluation process is on revisions to future materials. This requires that the instructional design principles on which materials are based be carefully validated to ensure that problems are the exception rather than the rule.

Before regular broadcasts began, the RLAP spent more than a year developing pilot radio lessons based on tentative principles about the most effective use of radio for teaching English as a foreign language, testing those lessons in classrooms, evaluating the results, revising the design principles, and so on. The result was a reasonable certainty that the radio lessons would be generally successful without an unacceptably high level of revision. In practice, this has proved to be the case. The radio lessons work well, and those problems identified by formative evaluation have been corrected without undue difficulty.

\subsection{Summative evaluation}

The project uses a set of twenty-one schools for both control and experimental purposes, adminis- 
tering a post-test after one year to children who have not been exposed to the treatment and the next year to children in the same grade or standard who have been exposed to the radio lessons. This lapped-year design was chosen for two major reasons. The paucity of reliable data on school, teacher and pupil quality, made any attempt to construct a comparable set of control and experimental schools impossible. The lapped-year design should ensure a closer match between control and experimental groups at the same schools than would be the case if two different sets of schools were used.

The second reason is that the lapped-year design completely avoids the problem of contamination of control schools. Control groups are tested before the broadcasts to their grade or standard begin, so there is no chance that they can be exposed to the treatment - the radio lessons - unintentionally.

The summative evaluation strategy for one classroom (the basic unit of analysis) is summarized in the following table.

\section{Summative Evaluation Design for One Classroom}

Year Radio Classrooms Control Classrooms (experimental) (control)

1981

(no broadcasts)

Classroom 1

1982

(standard 1

broadcasts)

1983

(standard 2 broadcasts)

1984

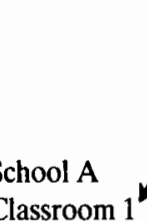

School A

Classioom 1

Teacher X

Pupil cohort alpha

$\begin{array}{cl}1984 & \text { School A } \\ \text { (standard } 3 & \text { Classroom } 3 \\ \text { broadcasts) } & \text { Teacher Z } \\ & \text { Pupil cohort beta }\end{array}$

In November 1981, pupils in the alpha cohort in classroom 1 of this school (school A), having been taught for a year by teacher $\mathrm{X}$ without the radio
English lessons, were given a post-test based on the Kenyan syllabus. Results from this test provided a pupil achievement record for the control group. In November, 1982, the same test was administered to pupils in the beta cohort. These children had spent a year in the same classroom (classroom 1) with the same teacher (teacher X), but with the radio English lesson treatment. Their test results provided a pupil achievement record for the experimental group. The amount of time devoted to English each week was held constant from 1981 to 1982. A comparison of results between the control and experimental groups (as indicated by the arrow) was then used to evaluate the effectiveness of this use of instructional radio (Academy for Educational Development 1981).

The same pattern was followed during 1983 and 1984. Pupil achievement and other variables will be measured in one year for control purposes and in the subsequent year, after treatment, for experimental purposes. The same control and experimental cohorts of children will be followed because the RLAP is interested in cumulative results (that is the effects of three years of radiobased instruction versus three years of conventional instruction).

Other methods of evaluating the project are also being used. For example, questionnaires distributed to teachers and headmasters at the end of each broadcast year measure attitudes towards the radio method on the part of school staff. Information about each school (such as repeater and drop-out rates, and attendance) is being gathered for future analysis. Finally, a cost-effectiveness analysis will be undertaken to consider the costs of delivering radio-based English instruction compared to the costs of delivering conventional instruction. The costs of radio-based instruction will also be compared to pupil performance.

\section{Radio lessons}

The radio lessons are based on the Kenyan English syllabus, that is the lessons use the same linguistic content (vocabulary, structures) specified for all Kenyan government school pupils. The sequencing of the linguistic items- has been changed in order to use radio more effectively, however.

The thirty-minute lessons have a standard format. 
Each lesson is divided into major blocks of time and content, and each block is divided into smaller segments. A segment may take as little as ten to fifteen seconds, or as much as a few minutes. A block may consist of up to four segments lasting five or six minutes altogether. A typical block might consist of a transition segment, an instructional segment introducing new material, a song or game segment, and finally a short drill segment. All these might have a central linguistic point, for example, learning how to talk about events that took place in the past.

A fixed portion of air time is planned and allotted to each block and segment so that script writers know exactly how much material they have to produce for scripts each day and how much time they have to teach a particular item. Writing assignments are divided among the members of the writing team by means of these blocks and segments.

In addition to a standard format, a standard group of characters is used each year. In year two for example, Safiri and Tina are the designated programme co-hosts. They also interact with other characters in a typical rural community and with the children in the classroom. Another featured couple, Sara and Rono, keep a little shop where some of the language exchanges take place. The main secondary characters are the Hamisi familymother, father, son and daughter, grandmother, grandfather, an aunt and an uncle.

The settings most often used in the broadcasts are Sara and Rono's shop, the Hamisi family's house and community, and the classroom. The characters are used to give reality to the language use. New vocabulary and grammar are introduced in a social context that helps illustrate the meaning of the language.

The instructional segments are of course the heart of the lessons. New material is introduced and practised in one or two segments. Previously introduced material is maintained through direct and conscious practice in two additional segments. These initial and maintenance segments make up the major portion of the lessons.

In the first year, considerable attention is paid to listening skills. Pupils are expected to respond physically to language cues even before they can speak complete sentences of their own. There is considerable directed physical activity and a great deal of repetition built into drills, songs, and games.

Mother tongue is never spoken by the radio characters. Since Kenya has such a linguistic diversity, only English is used in the radio broadcast. The classroom teacher is directed by the radio to give explanations in the mother tongue when it is felt absolutely necessary. As the children gain language ability, there is less and less reliance on mother tongue directions and explanations.

The radio lessons introduce meaning through specific language and sound effects in communication settings. Even difficult linguistic concepts are introduced by the radio with the help of visual effects carried out in the classroom by the children. The concepts of more and less water, for example, are demonstrated by two pupils holding bottles filled in advance of the broadcast by the classroom teacher to represent more and less. The radio exercise then ensures that pupils understand the meaning and can speak sentences related to the situation.

A typical instructional segment, then, begins with a context for the language use. Next, the radio characters model the language. Then some form of practice is directed by the radio. Finally, the radio characters reinforce the correct responses. The classroom teacher helps model the children's behaviour but is never required to provide a language model for the children during the broadcasts. The language used in the broadcasts is academic English, that is language that is most useful in receiving instruction and reading textbooks in all subjects. Informal language is used in the family and community situations, but the linguistic content and the language functions are directly transferable to classroom learning through the medium of English.

The principal blocks of instruction over a period of several days contain the following types of activities which are familiar to language teachers:

- choral and individual question-and-answer exchanges between students and the radio

- structured conversation between the radio and the class or individuals 
- nonverbal responses to radio language cues

- dialogues or stories that engage the pupils as participants

- reading aloud and silently from worksheets and the blackboard

- displaying and manipulating common classroom objects

- songs and games, and

- pattern drils.

\section{Preliminary results}

Initial results are now available from the first year achievement tests and from the questionnaire distributed to teachers and headmasters after the first year of broadcasting. They show substantial achievement gains and strong support from school personnel (Owino \& Christensen 1983).

The year one achievement test consisted of forty questions measuring listening comprehension, based on English vocabulary and structures specified by the Kenyan syllabus. The test was developed by project staff with the help of outside consultants. It was administered at the end of 1981 to children in twenty-one project schools who had not heard the RLAP radio lessons. Exactly the same test was given to children in the same twenty-one project schools at the end of 1982. These children had used the radio method to learn English.

Although reading was not introduced in the grade one radio lessons until term three, children learning English by radio showed a $22.5 \%$ gain over children in the conventional classes. The results for listening comprehension were even more favourable. Radio pupils showed a $50 \%$ gain. In other words, the intensive radio method of teaching English produced substantial gains in pupil performance after only one year of broadcasts. Improvement was found in every district and every vernacular language group represented in the project, and for schools scoring high, medium and low on the national primary school leaving examination.

The questionnaires completed by teachers and headmasters showed that the radio English lessons have been very well received.

$-89 \%$ of those expressing an opinion rated the radio lessons as "good" or "excellent". No one rated them "poor".

$-99 \%$ of those responding felt that the radio pupils spoke better English after one year than pupils who had not had the radio lessons. $90 \%$ felt that the radio pupils would be ready to use English as the sole medium of instruction after standard three.

These first year results along with anecdotal evidence from schools strongly suggest that intensive instructional radio will prove to be an effective tool for teaching English to rural primary school children. Pupils have already demonstrated significant gains in listening and reading comprehension. Teachers, headmasters and parents are convinced that this method works. They see an improvement in their children's English, and they want to continue with the project.

\section{Conclusion}

The Radio Language Art Project in Kenya, demonstrates that radio can be used effectively in teaching language at the primary level in a rural setting. The implications for the developing world, where human and material resources are scarce or poorly distributed, is obvious. Implications of this project for European and North American language educators are less dramatic, but the strengths of radio to reach certain target audiences is one significant conclusion from the Kenya project. Carefully designed, written, and produced radio lessons, aided by human interaction fostered by a teacher or other guide, can be an effective alternative to the more complex and more expensive newer technologies. In addition to being less threatening to teachers, simpler technologies such as radio may be less confusing and more effective for learners.

\section{Bibliography}

ACADEMY FOR EDUCATIONAL DEVELOPMENT 1981. Radio language arts implementation plan. Washington, DC: Academy for Educational Development.

FRIEND, J. 1980. A historical view of the radio 
mathematics project's use of formative evaluation. In Friend, J., Searle, B. \& Suppes, P. (eds.), Radio mathematics in Nicaragua. Stanford: Institute for Mathematical Studies in the Social Sciences.

FRIEND, J., SEARLE, B. \& SUPPES, P. (eds.) 1980. Radio mathematics in Nicaragua. Stanford:
Institute for Mathematical Studies in the Social Sciences.

OWINO, G. \& CHRISTENSEN, P.R. 1983. The radio language arts project - results from the firs year of broadcasting: a preliminary report. Washington, DC: Academy for Educational Development.

THE ACCELERATING advance of humanity in history shows there is no end to the possibilities for transformation.

Science is constantly shrinking the realm of the impossible.

If something is true in theory, it must also be true in practice.

The dreams of men have no limit.

Events have always surpassed the most imaginative conceptions of the future.

We will never imagine anything quite as fantastic as reality.

Reality is revolutionary.

The most revolutionary of all. 